\title{
Pain Perception following Administration of Propofol with 7.5 mg Ephedrine, 15 mg Ephedrine, or Lignocaine- A Comparative Study
}

\author{
${ }^{1}$ Indrani H Chincholi, ${ }^{2}$ Harprit K Madan, ${ }^{3}$ Sonali D Patira
}

\begin{abstract}
Introduction: Propofol is the drug of choice for induction of anesthesia because of its rapid onset, easy titration, and short duration of action. However, pain on propofol injection is an unpleasant experience felt by many of our patients. Many factors have been investigated to decrease the pain on propofol injection but it is still a mystery.
\end{abstract}

Aim: To compare the effect of two doses of ephedrine (7.5 and $15 \mathrm{mg}$ ) and lignocaine on pain during injection of propofol and to compare their hemodynamic parameters and note for any complications.

Materials and methods: This study was a prospective, randomized, double-blinded, single-center study on 150 adult patients of both the sexes belonging to American Society of Anesthesiologists (ASA) grades I and II for elective surgery under general anesthesia. The aim was to compare the analgesic effect of lignocaine, ephedrine 7.5 and $15 \mathrm{mg}$ in ameliorating propofol injection pain. About 50 patients were allocated to each of the three groups receiving lignocaine $2 \%(1.5 \mathrm{~mL})$, ephedrine $7.5 \mathrm{mg}$, and ephedrine $15 \mathrm{mg}$ intravenously admixed with propofol. The intensity of pain at the time of propofol injection was assessed using verbal rating scale (VRS) 4-point scale before the patient lost consciousness.

Statistical analysis: Statistical analysis was done by using Statistical Package for the Social Sciences (SPSS) version 22.0 software. The qualitative data were summarized as frequency and percentages. The Fischer exact test was used to analyze the data. The continuous data were summarized as mean and standard deviation. The group and intergroup analyses were done using repeated measures analysis of variance (ANOVA) test. A p-value $<0.05$ was considered significant.

${ }^{1}$ Professor and Head, ${ }^{2}$ Associate Professor, ${ }^{3}$ Junior Consultant

${ }^{1}$ Department of Anesthesiology, Seth Gordhandas Sunderdas Medical College and King Edward Memorial Hospital, Mumbai Maharashtra, India

${ }^{2}$ Department of Anesthesiology, Hinduhrudaysamrat Balasaheb Thackarey Medical College and Dr. Rustom Narsi Cooper Municipal General Hospital, Mumbai, Maharashtra, India

${ }^{3}$ Department of Anesthesiology, Jupiter Hospital, Mumbai Maharashtra, India

Corresponding Author: Harprit K Madan, 101/B, Cosmos APTS. 3rd Cross Lane, Lokhandwala Complex, Andheri West Mumbai-400053, Maharashtra, India, Phone: +919830091317 e-mail: drpreet@hotmail.com
Results: Median (interquartile range) of the pain score was 1 (2) in group E-7.5 mg, 0 (1) in group E-15 mg, and 0(1) in group L. Results were statistically significant.

Conclusion: Adding $15 \mathrm{mg}$ ephedrine was as effective as adding lignocaine for the prevention of propofol injection pain and ephedrine had a better and stable hemodynamic profile.

Keywords: Ephedrine, Pain, Propofol.

How to cite this article: Chincholi IH, Madan HK, Patira SD. Pain Perception following Administration of Propofol with $7.5 \mathrm{mg}$ Ephedrine, $15 \mathrm{mg}$ Ephedrine, or Lignocaine-A Comparative Study. Res Inno in Anesth 2017;2(2):58-63.

Source of support: Nil

Conflict of interest: None

\section{INTRODUCTION}

Propofol is the most frequently used intravenous (IV) anesthetic agent today. It is the drug of choice for induction of anesthesia in millions of patients every year because of its rapid onset, shorter duration of action, easy titration, and favorable profile for side effects. ${ }^{1}$ One of the disadvantages of propofol is the pain caused during injection. ${ }^{1}$ The pain that occurs in 26 to $90 \%$ of patients may be severe enough to add to patients' stress from anesthesia and surgery and most probably will be recalled in the recovery room. Some patients do recall the induction of anesthesia as the most painful part of the perioperative period. ${ }^{2}$ As a result, many interventions have been investigated for the alleviation of the pain associated with propofol injection. A systematic review in 2000 suggested pretreatment using lidocaine (lignocaine) in conjunction with venous occlusion as one of the most effective interventions. ${ }^{3}$ Despite that recommendation, the venous occlusion technique failed to gain widespread popularity. Pretreatment with lignocaine has been the most common proposed treatment to decrease injection-related pain; but unfortunately, the failure rate is between 13 and $32 \%{ }^{2}$ In addition, it does not prevent hypotension caused by propofol during induction. ${ }^{4}$ Ephedrine is a sympathomimetic amine, used as a stimulant, an appetite suppressant, and a decongestant. ${ }^{5}$ It has been used for many years to counteract hypotension and bradycardia in spinal and epidural anesthesia. ${ }^{6}$ Ephedrine acts directly at both alpha- and beta-adrenoceptors and indirectly by releasing 
endogenous norepinephrine. ${ }^{5}$ However, recent evidences indicate that ephedrine may reduce the pain of propofol injection and also counteract the hypotension associated with propofol anesthesia. ${ }^{4}$ However, the number of studies about ephedrine's effect on propofol-induced pain from injection is very limited. In order to broaden the understanding about ephedrine and its relation with propofol injection pain, this study was undertaken to find the effect of ephedrine coadministered with propofol. At the same time, the study wished to address the question of the optimum dose of ephedrine to alleviate pain on propofol injection.

\section{AIMS AND OBJECTIVES}

To compare the effect of two doses of ephedrine (7.5 and $15 \mathrm{mg}$ ) and lignocaine on pain during injection of propofol and to determine the optimum dose of ephedrine required. The secondary objective is to compare the changes in the hemodynamic parameters associated with the injection in each treatment group.

\section{MATERIALS AND METHODS}

This was a prospective, randomized double-blinded, single-center study. It was conducted in a major tertiary care teaching hospital after institutional ethics committee approval. One hundred fifty subjects were randomly divided into three groups of 50 patients each.

1. Group E-7.5: IV propofol (1\%) $18.5 \mathrm{~mL}$ ephedrine $7.5 \mathrm{mg}(0.25 \mathrm{~mL}) 1.25 \mathrm{~mL} \mathrm{NS}=20 \mathrm{~mL}$

2. Group E-15: IV propofol (1\%) $18.5 \mathrm{~mL}$ ephedrine $15 \mathrm{mg}(0.5 \mathrm{~mL}) 1.0 \mathrm{~mL} \mathrm{NS}=20 \mathrm{~mL}$

3. Group L: IV propofol (1\%) $18.5 \mathrm{~mL}$ lignocaine (2\%) $1.5 \mathrm{~mL}=$ total $20 \mathrm{~mL}$.

The inclusion criteria were ASA grades I and II with age between 18 and 60 years and body mass index (BMI) between 19 and $30 \mathrm{~kg} / \mathrm{m}^{2}$. Patients with documented uncontrolled hypertension, ischemic heart disease, on beta-blockers, with left ventricular ejection fraction less than $45 \%$, with abnormal electrocardiogram (ECG) characteristics, peripheral vascular disease, thyrotoxicosis, neurological, hepatic, or renal diseases, chronic pain syndrome, known allergy to the study medications, pregnant patients or patients undergoing revision or emergency surgery, or patients who required preoperative inotropic, vasopressor, mechanical circulatory, or ventilator support were excluded from the study. If the patient could not be intubated in the first attempt or if a gum-elastic bougie was used, he/she was excluded from the study. After obtaining informed consent, a detailed clinical history and clinical examination was conducted preoperatively a night before the surgery was planned. Routine investigations were done. Patients were kept nil by mouth from night $10 \mathrm{pm}$. Before taking the patient to the operation theater, they were explained the whole procedure and how to grade pain based on the VRS during propofol injection. Standard monitors ECG, peripheral capillary oxygen saturation $\left(\mathrm{SpO}_{2}\right)$, and noninvasive blood pressure measuring cuff were attached to the patients. A 20 gauge IV catheter was inserted on the dorsum of the hand. Preloading with $15 \mathrm{~mL} / \mathrm{kg}$ of Ringer's lactate was done. Intravenous glycopyrrolate $4 \mu \mathrm{g} / \mathrm{kg}$ was given to all the patients. Patients were preoxygenated with $100 \%$ oxygen for 3 minutes. For induction a syringe containing $18.5 \mathrm{~mL}$ of propofol and $1.5 \mathrm{~mL}$ of the test drug selected by computer-generated randomization was used. The admixture was then injected through a three-way tap directly connected to the IV catheter at $1 \mathrm{~mL} / \mathrm{s}$, with the IV infusion line closed. During the study the anesthetist recording the pain score and the hemodynamics was kept blinded about the drug given along with propofol. During the study, the blinded anesthesiologist asked the patient to evaluate the pain score VRS every 5 seconds during propofol injection graded as 0 to 3 and then recorded the highest degree of pain over a period of 30 seconds or till the patient lost consciousness, whichever was earlier. The loss of consciousness was determined by absence of palpebral reflex and corneal reflex. For evaluation of pain, the grading criteria of VRS as advocated by McCirrick and Hunter ${ }^{7}$ were used every 5 seconds during propofol injection graded as 0 to 3 in accordance and then the highest degree of pain was recorded. The grading criteria of VRS were as follows: $0=$ no pain experienced, $1=$ patients complained of mild pain or soreness, $2=$ moderate pain complaint by patients, and 3 = severe pain associated with grimacing, withdrawal movement of forearm, or both. After the propofol injection and the loss of consciousness and with confirmation of ventilation, vecuronium $0.08 \mathrm{mg} / \mathrm{kg}$ was injected intravenously to facilitate controlled ventilation. About $50 \%$ nitrous oxide in oxygen was given for 2 minutes and 100\% oxygen for the next 1 minute. Trachea was intubated with the appropriatesized cuffed endotracheal tube using Macintosh laryngoscope. Anesthesia was maintained on $1 \%$ isoflurane and vecuronium. The heart rate (HR) and blood pressure (BP) were monitored postinduction every minute for the next 10 minutes. Any fall in HR more than $20 \%$ from baseline was treated with $100 \mathrm{~mL}$ of fluid challenge. The drug accountability and storage were maintained by the use of drug dispensing logs as per compliance with Good Clinical Practice guidelines.

\section{STATISTICAL ANALYSIS}

Statistical analysis was done using SPSS version 22.0 software. The qualitative data were summarized as frequency and percentages. Fischer exact test was used 
to analyze the data. The continuous data were summarized as mean and standard deviation. The groups and intergroup analysis were done using repeated measures ANOVA test. A p-value $<0.05$ was considered significant.

\section{RESULTS}

There were no significant differences in sex, age, height, and weight, ASA status among the three groups, and all the three groups were comparable (Table 1).

\section{Pain Score Verbal Rating Scale}

Median (interquartile range) of the pain score was 1 (2) in group E-7.5, 0 (1) in group E-15 mg, and 0 (1) in group L (Table 2). The Kruskal-Wallis shows a significant difference in the pain scores between the treatment groups (test statistic $=18.1, \mathrm{df}=2, \mathrm{p}<0.0005)$. Post hoc Dunn's test shows that a significantly higher pain score was recorded in treatment group E-7.5 as compared with treatment groups E-15 ( $\mathrm{p}=0.004)$ and $\mathrm{L}(\mathrm{p}<0.0005)$ (Table 2$)$. There was no statistically significant difference in the pain scores in treatment groups E-15 and L. Ephedrine $15 \mathrm{mg}$ has a greater effect on pain relief as compared with ephedrine $7.5 \mathrm{mg}$. Lignocaine had a greater effect on pain relief as compared with ephedrine $7.5 \mathrm{mg}$. No significant difference between E-15 and L groups was found.

\section{HR from Baseline to 10th Minute (Mean \pm SD)}

All groups showed a similar pattern in the HR. Intubation (3rd minute) caused a sudden increase in HR in all the three groups (Graph 1). The maximum increase in HR during intubation was in the ephedrine $15 \mathrm{mg}$ group (89.9), while the minimum increase was in the ephedrine $7.5 \mathrm{mg}$ group (86.4). Repeated measures ANOVA was used to compare the HR between the three groups at each point in time. No significant difference was noted between the heart rate at any minute.

\section{Mean Blood Pressure $(\mathrm{mm} \mathrm{Hg})$}

Both the E-7.5 mg (82) and the L (76.5) groups had an initial fall in mean blood pressure (MBP); however, in the ephedrine $15 \mathrm{mg}$ group there was an initial increase in MBP (Graph 2). Each group E-7.5 (88.4), E-15 (90.4), and L (85.1) had a peak in the MBP immediately after intubation was done. Intubation was done in the third minute- the effect of which was reflected in the 4 th minute readings

- There was a fall in MBP in the 5th minute.

- The MBP again had an increasing trend after the 6th to 8 th minute and peaked at around the 9th to 10th minute.

- Repeated measures ANOVA was used to compare the $\mathrm{BP}$ between the three groups at each point in time

Table 1: Group-wise demographic data (mean \pm SD)

\begin{tabular}{lllll}
\hline & Group E-7.5 & Group E-15 & Group L & $p$-value \\
\hline Age (years) & $53.5 \pm 1.4$ & $54.9 \pm 3.5$ & $53.6 \pm 1.9$ & 0.63 \\
Males (\%) & 64 & 58 & 60 & 0.37 \\
Females (\%) & 36 & 42 & 40 & \\
Weight (kg) & $57.3 \pm 11.9$ & $54.8 \pm 9.5$ & $61.74 \pm 8.5$ & 0.98 \\
Height (m) & $1.50 \pm 0.07$ & $1.59 \pm 0.09$ & $1.59 \pm 0.08$ & 0.48 \\
$\mathrm{BMI}\left(\mathrm{kg} / \mathrm{m}^{2}\right)$ & $25.26 \pm 2.26$ & $24.09 \pm 1.84$ & $25.27 \pm 1.91$ & 0.47 \\
$\mathrm{HR}($ beats/min) & $80.6 \pm 3.84$ & $81.0 \pm 4.15$ & $80.7 \pm 2.91$ & 0.53 \\
$\mathrm{Mean} \mathrm{HR}(\mathrm{mm} \mathrm{Hg})_{\mathrm{SpO}}$ & $86.2 \pm 5.29$ & $86.1 \pm 5.13$ & $86.2 \pm 4.42$ & 0.57 \\
\hline
\end{tabular}

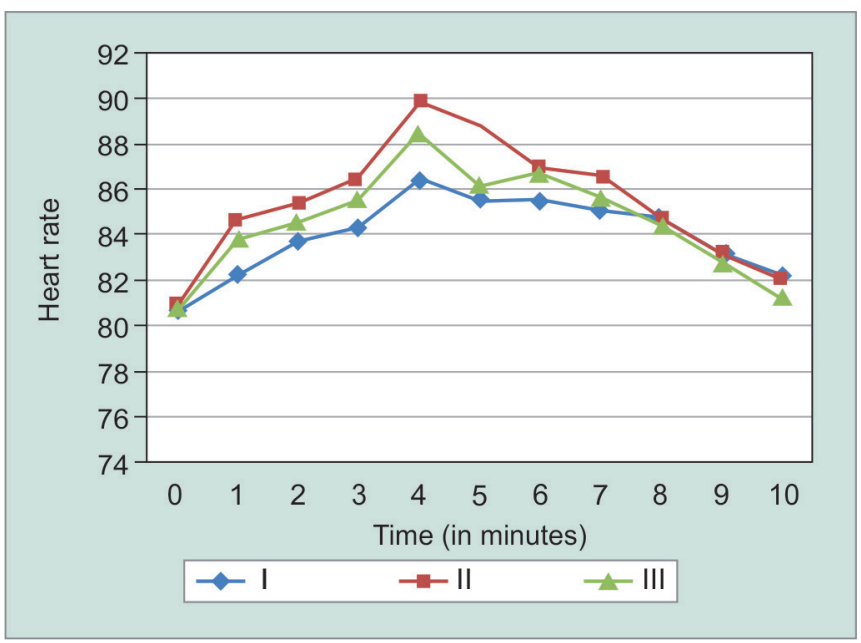

Graph 1: Mean heart rate from baseline to 10th minute

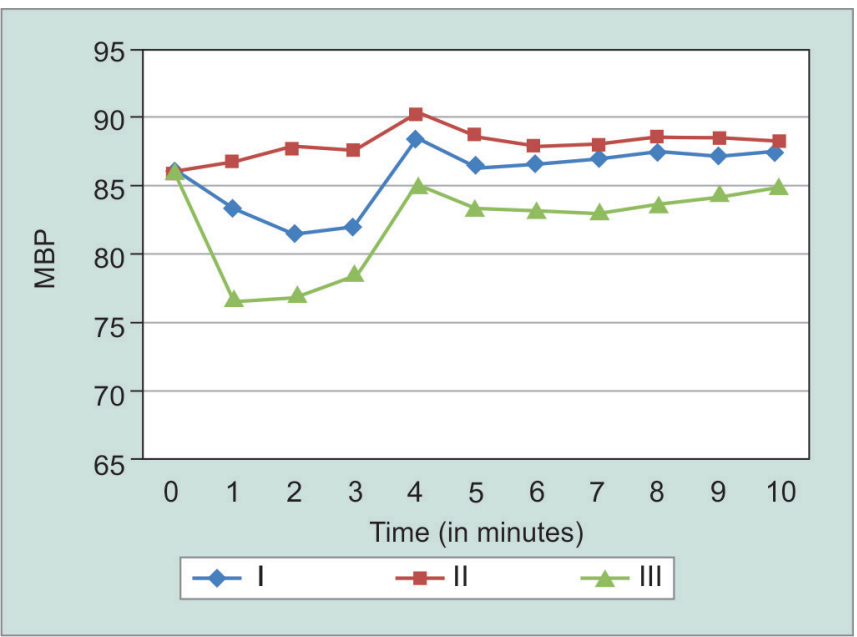

Graph 2: Trends in mean blood pressure over 10 minutes 
Table 2: Number of patients feeling pain on injection (number/\%)

\begin{tabular}{lllll}
\hline & $\begin{array}{l}\text { Group 7.5 } \\
(n=50)\end{array}$ & $\begin{array}{l}\text { Group 15 } \\
(n=50)\end{array}$ & $\begin{array}{l}\text { Group L } \\
(n=50)\end{array}$ & All groups \\
\hline No pain (score 0) & $19(38)$ & $26(52)$ & $33(66)$ & $78(52)$ \\
Mild pain (score 1) & $8(16)$ & $24(48)$ & $14(28)$ & $46(30.7)$ \\
$\begin{array}{l}\text { Moderate pain } \\
\text { (score 2) }\end{array}$ & $23(46)$ & $0(0)$ & $3(6)$ & $26(17.3)$
\end{tabular}

Fisher's exact test value $=20, p$-value $<0.0005$, significant; No participant with severe pain-score 3 in any of the groups.

and the MBP values for the first 8 minutes showed a significant rise in MBP in groups with ephedrine as additive as compared with lignocaine group at all time points.

During the study none of the subjects experienced any arrhythmias, persistent tachycardia, and allergic reaction to any test drug. Hypotension ( $>20 \%$ fall from baseline) was seen in two patients belonging to the lignocaine group in the 2nd minute postinduction, which responded to fluid challenge. There was hence, no statistical significance in occurrences of adverse events.

\section{DISCUSSION}

Propofol is an ultra-short-acting anesthetic IV induction agent. It is being used increasingly for day-care surgery, conscious sedation total IV anesthesia, and maintenance of anesthesia. It is also being used for prevention of emesis, for tracheal intubation, and laryngeal mask airway insertion without the use of neuromuscular blockers. It is also used for treatment of pruritus. ${ }^{8}$ It possesses many characteristics of an ideal anesthetic induction agent with regard to its immediate return of consciousness, recovery of protective reflexes, and resumption of motor activity. It causes hypnosis in one arm-brain circulation time with minimum excitation. The most common side effect seen is pain on its injection, the incidence of which is between 28 and $91 \%$ in adults ${ }^{9}$ and specifically between 40 and $86 \%$ in a hand vein. ${ }^{10}$ Pain during injection could be severe enough to cause life-threatening complications. Ahed Zeidan ${ }^{11}$ reported a case report of profound pain on propofol injection which triggered severe bronchospasm in a smoker. Morishima et al ${ }^{12}$ have reported a case of myocardial ischemia attack due to profound propofol injection pain.

\section{Probable Mechanisms of Pain on Injection of Propofol}

Probable mechanisms of pain are activation of pain mediators (kininogens), endothelial irritation, the osmolality differences, and nonphysiological $\mathrm{pH}$ of the formulation. ${ }^{8}$ Various strategies that have been advocated to prevent pain on injection of propofol are ${ }^{8}$ (1) physical methodssite of injection (big size vein), speed of injection of propofol, speed of carrier IV fluid, dilution of propofol, different temperatures of propofol, different syringe material, and aspiration of blood to dilute propofol; (2) use of local anesthetics-lignocaine: Pretreatment or mixed with propofol, procaine, or EMLA cream; (3) use of other drugs: Aspirin and nonsteroidal anti-inflammatory drugs or premedication with alfentanyl, fentanyl, or pethidine, other drugs like metoclopramide, glyceryl trinitrate, thiopental sodium, ketamine, or ephedrine; (4) from the above strategies, lignocaine is most commonly used. Several studies are available in which lignocaine is used for the attenuation of pain on injection of propofol. A systemic review and meta-analysis done by Jalota et $\mathrm{a} \mathrm{l}^{13}$ concluded that lignocaine was one of the efficacious adjuvants for prevention of propofol injection pain. Propofol can cause hypotension with an initial increase in HR and cardiac output and then with a subsequent decrease to less than baseline. ${ }^{1}$ Lignocaine when used with propofol does not prevent the fall in HR caused by propofol. ${ }^{4}$ Ephedrine, which acts directly at both $\alpha$ and $\beta$ receptors and indirectly by releasing endogenous norepinephrine, has been used for many years to counteract hypotension and bradycardia in spinal and epidural anesthesia. ${ }^{6}$ Gamlin et $\mathrm{al}^{14}$ studied the hemodynamic effects of propofol in combination with ephedrine. They concluded that addition of ephedrine to propofol appeared to be an effective method of obtunding the hypotensive response to propofol at all doses used in this study. Cheong et $\mathrm{al}^{4}$ concluded that pretreatment with a small dose of ephedrine (30 and $70 \mu \mathrm{g} / \mathrm{kg}$ ) reduced the incidence and intensity of propofol-induced pain with a lesser decrease in arterial HR than from propofol alone in lidocaine pretreatment. Lee and Russell ${ }^{15}$ recommended that lignocaine should be added to propofol for induction rather than given before induction. The average pain score of the patients receiving ephedrine $7.5 \mathrm{mg}$ was 1.08 , with $38 \%$ patients experiencing no pain, $16 \%$ of patients experiencing mild pain (pain score: 1 ) and $46 \%$ experiencing moderate pain (pain score: 2). Ephedrine $15 \mathrm{mg}$ gave an average score of 0.48 , with $48 \%$ of patients experiencing mild pain (pain score: 1). None experienced moderate-to-severe pain. With lignocaine $2 \% 1.5 \mathrm{~mL}$, an average pain score of 0.40 was obtained, with $28 \%$ experiencing mild pain (pain score: 1 ) and $6 \%$ experiencing moderate pain (pain score: 2). Based on the mean score and the significance level ephedrine $15 \mathrm{mg}$ and lignocaine $30 \mathrm{mg}$ had a greater effect on pain relief as compared with ephedrine $7.5 \mathrm{mg}$, with a p-value of 0.0213 . There is no significant difference between lignocaine and ephedrine $15 \mathrm{mg}$. Incidence of pain was $34 \%$ with lignocaine and $42 \%$ with ephedrine $15 \mathrm{mg}$, which was comparable with the results of Austin and Parke. ${ }^{16}$ They found an incidence of pain of $31.4 \%$ with lignocaine, $35.3 \%$ with ephedrine $15 \mathrm{mg}$, and $35.3 \%$ 
with ephedrine $30 \mathrm{mg}$. Cheong et al ${ }^{4}$ found that the incidence of pain was $43.3 \%$ in lignocaine group and $35.6 \%$ in ephedrine $30 \mu \mathrm{g} / \mathrm{kg}$. Hemodynamic HR and mean arterial $\mathrm{BP}$ were measured before induction followed by every 1 minute interval for 10 minutes postinduction. All groups showed a similar pattern in the HR. Intubation caused a sudden increase in HR in all the three groups. The maximum increase in HR during intubation was in the ephedrine $15 \mathrm{mg}$ group with a change from 81 at baseline to 89.9 in the 4 th minute. The minimum increase was in the ephedrine $7.5 \mathrm{mg}$ group from 80.6 at baseline to 86.4 in the 4th minute. In the lignocaine group, HR changed from a baseline of 80.7 to 88.5 in the 4th minute. When the ANOVA test was applied in all the minutes among the three groups, there was no significant difference between the HR at any minute. Austin and Parke ${ }^{16}$ also observed no significant change in HR in all three groups. The absence of intubation response may be due to the use of fentanyl in the premedication. They also observed that ephedrine $30 \mathrm{mg}$ with propofol had the least amount of hemodynamic changes. ${ }^{16}$ Cheong et al ${ }^{4}$ observed the HR increasing from baseline value of around $78 /$ minute to $75 /$ minute postinduction in the lignocaine group and baseline of $76 /$ minute to $78 /$ minute postinduction in the ephedrine $30 \mu \mathrm{g} / \mathrm{kg}$ group. Postintubation, the HR shot up to around 85 in both the groups. The changes in HR were insignificant. Khezri and Kayalha ${ }^{17}$ observed that HR changes, before and after propofol injection, tended to be smaller in ephedrine groups than in the lignocaine and saline groups. Blood pressure-both propofol with ephredrine $7.5 \mathrm{mg}$ and with lignocaine showed an initial fall in BP following induction while there was no fall in $\mathrm{BP}$ with ephredrine $15 \mathrm{mg}$. There was rise in BP following intubation in all three groups; however, it decreased gradually within 2 minutes. There was a significant difference between the MBP in the E-7.5 and E-15 mg groups as compared with the L group. There was no significant difference between MBP in both the E groups. We did not find any adverse hemodynamic effects after tracheal intubation in groups with pretreatment of ephedrine, such as severe hypertension, tachycardia, or arrhythmias. Gamlin et $\mathrm{al}^{14}$ studied the hemodynamic effects of propofol with ephedrine and reported that the propofol-ephedrine combination is chemically compatible and stable and maintains BP and cardiac output without tachycardia or other adverse effects. Cheong et al ${ }^{4}$ found that before intubation, MAP was significantly decreased in the P and L groups compared with values before induction $(\mathrm{p} \leq 0.05)$; however, it was maintained in both the ephedrine groups. But after intubation, MAP and HR variables in the E110 (ephedrine $110 \mu \mathrm{g} / \mathrm{kg}$ ) and E150 (ephedrine $150 \mu \mathrm{g} /$ $\mathrm{kg}$ ) groups were significantly higher than in the $\mathrm{P}$ and $\mathrm{L}$ groups, respectively ( $p \leq 0.05)$. A small dose of ephedrine
(30 and $70 \mu \mathrm{gg} / \mathrm{kg}$ ) could prevent propofol-induced hypotension before intubation and did not produce significant hemodynamic changes compared with the other groups after intubation. However, the hemodynamics were monitored for only 3 minutes postinduction. Gamlin et $\mathrm{al}^{14}$ concluded that ephedrine added at $0.5 \mathrm{mg} / \mathrm{mL}$ of propofol was not as effective in overcoming hypotension as 0.75 or $1.0 \mathrm{mg} / \mathrm{mL}$ were. Austin and Parke ${ }^{16}$ found that ephedrine $1.5 \mathrm{mg} / \mathrm{mL}$ of propofol gave the most stable hemodynamic profile, and none of the patients required hemodynamic rescue. In the lignocaine group, 6 out of 50 patients required hypotension rescue. Both doses of ephedrine 7.5 and $15 \mathrm{mg}$ per $20 \mathrm{~mL}$ of propofol gave a stable hemodynamic profile with no fall in MAP postinduction as seen in the lignocaine group.

\section{CONCLUSION}

We conclude that adding $15 \mathrm{mg}$ ephedrine was as effective as adding lignocaine for the prevention of propofol injection pain, and ephedrine had a better and a stable hemodynamic profile. Thus, the use of $15 \mathrm{mg}$ ephedrine mixed in propofol can prevent pain and at the same time maintain hemodynamic stability during induction.

\section{REFERENCES}

1. Miller RD. Miller's anaesthesia. 7th ed. Philadelphia, PA: Churchill Livingstone; 2009. p. 720-728.

2. Massad IM, Abu-ali HM, Abu-Halaweh SA, Badran IZ. Venous occlusion with lignocaine for preventing propofol induced pain. A prospective double-blind randomized study. Saudi Med J 2006 July;27(7):997-1000.

3. Picard P, Tramer MR. Prevention of pain on injection with propofol: a quantitative systematic review. Anesth Analg 2000 Apr;90(4):963-969.

4. Cheong MA, Kim KS, Choi WJ. Ephedrine reduces the pain from propofol injection. Anaesth Analg 2002 Nov;95(5): 1293-1296.

5. Brian BH. Adrenoreceptor-activating and other sympathomimetic drugs. In Bertram GK, editor. Basic \& clinical pharmacology. 10th ed. New York, NY: McGraw-Hill Publications; 2007.

6. Hemmingsen C, Poulsen JA, Risbo A. Prophylactic ephedrine during spinal anaesthesia: double-blind study in patients in ASA groups I-III. Br J Anaesth 1989 Sep;63(3):340-342.

7. McCirrick A, Hunter S. Pain on injection of propofol: the effect of injectate temperature. Anesthesia 1990 Jun;45:443-444.

8. Tan $\mathrm{CH}$, Onsiong MK. Pain on injection of propofol. Anaesthesia 1998 May;53(5):468-476.

9. King SY, Davis FM, Wells JE, Murchison DJ, Pryor PJ. Lidocaine for the prevention of pain due to injection of propofol. Anaesth Analg 1992 Feb;74(2):246-249.

10. Angst MS, Mackey SC, Zupfer GH, Tataru CD, Brock-Utne JG. Reduction of propofol injection pain with a double lumen i.v. set. J Clin Anesth 1997 Sep;9(6):462-466.

11. Zeidan A. Profound pain due to propofol injection triggered bronchospasm in a smoker-a case report. Middle East J Anaesthesiol 2006 Jun;18(5):939-942. 
12. Morishima T, Sobue $\mathrm{K}$, Arima H, Tanaka S, So M, Ando H, Katsuya $\mathrm{H}$. Profound pain due to propofol injection triggered myocardial ischemia in a patient with a suspected pheochromocytoma. Anesth Analg 2003 Feb;96(2):631.

13. Jalota L, Kalira V, George E, Shi YY, Hornuss C, Radke, Pace NL, Apfel CC. Prevention of pain on injection of propofol: systematic review and meta-analysis. BMJ 2011 Mar;342:d1110.

14. Gamlin F, Vucevic M, Winslow L, Berridge J. The haemodynamic effects of propofol in combination with ephedrine. Anaesthesia 1996 May;51(5):488-491.
15. Lee P, Russell WJ. Preventing pain on injection of propofol: a comparison between lignocaine pre-treatment and lignocaine added to propofol. Anaesth Intensive Care 2004 Aug;32(4):482-484.

16. Austin JD, Parke TJ. Admixture of ephedrine to offset side effects of propofol: a randomized, controlled trial. J Clin Anesth 2009 Feb;21(1):44-49.

17. Khezri MB, Kayalha $\mathrm{H}$. The effect of combined ephedrine and lidocaine pretreatment on pain and hemodynamic changes due to propofol injection. Acta Anaesthesiol Taiwan. 2011 Jun; 49(2):54-58. 